\title{
A three-dimensional analysis of fatigue crack paths in thin metallic sheets
}

\author{
J.B. Esnault ${ }^{1,2}$, V. Doquet ${ }^{1}$, P. Massin ${ }^{2}$ \\ ${ }^{1}$ : Laboratoire de Mécanique des Solides, CNRS, Ecole Polytechnique, Palaiseau \\ France, doquet@1ms.polytechnique.fr, esnault@1ms.polytechnique.fr \\ ${ }^{2}$ LaMSid, EDF - CNRS - CEA, Clamart, France, patrick.massin@edf.fr
}

ABSTRACT. Fatigue crack growth in thin sheets of 7075 T651 aluminium alloy and
S355 steel were characterized in $3 D$, using crack front markings and topographic
reconstructions of fracture surfaces. Tests in air or in salt water produced different
crack paths for similar mechanical conditions, shear lips being reduced by the
corrosive environment, in the aluminium alloy as well as in steel. Before the onset of
shear lips development, tunnelling crack fronts were observed, but tunnelling was
progressively reduced and cancelled as slanted crack growth developed, even though
$\Delta K_{I}$ is reduced by crack twisting. This indicates a significant contribution of shear
modes to the crack driving force, even though mode I striations are still present on
slanted zones. $\Delta K_{I}, \Delta K_{I I}$ and $\Delta K_{I I I}$ were computed by X-FEM taking into account the
real crack path. The crack growth rates correlated much better to
$\Delta K_{e q}=\sqrt{\Delta K_{I}^{2}+\Delta K_{I I}^{2}+\frac{\Delta K_{I I I}^{2}}{(1-v)}}$ than to $\Delta K_{I}$. Elastic-plastic finite element simulations and the local application of a fatigue criterion with an amplitude-dependent critical plane qualitatively captured the transition in fracture mode in 7075 T651.

\section{INTRODUCTION}

Fatigue crack growth normal to the tensile axis becomes unstable in thin metallic sheets, above a material, environment and frequency-dependent amplitude. Shear lips development has been investigated mainly in aluminium alloys by Schijve and coworkers [1-2] or Zuidema et al. [3-4], while very few studies were devoted to steel [5] or titanium alloys [6]. These authors observed that shear lips started to develop when a threshold crack growth rate was reached ( 5 to $7.5 \mu \mathrm{m} /$ cycle in titanium alloys, according to Walker et al [6], about $0.1 \mu \mathrm{m} /$ cycle in aluminium alloys, according to Zuidema et al. [4], while Hudson and Scardina report 0.2 to $0.7 \mu \mathrm{m} /$ cycle for $7075-\mathrm{T} 6$ alloy [7]).

The analyses of experimental data in the literature are essentially two-dimensional. Slanted crack growth kinetic data is analysed as if it was mode I and as if the growth rate and driving force were uniform along the front. Based on "constant $\Delta K_{I}$ tests", empirical relations between the steady-state shear lips width, the loading frequency and 
the "effective $\Delta \mathrm{K}_{\mathrm{I}}$ " were derived for aluminium alloys [4-5]. This parameter will be denoted below by "apparent $\Delta \mathrm{K}_{\mathrm{I}}$ ", since it is computed in $2 \mathrm{D}$ for a normal crack of same length as that observed on the free surface, with an empirical correction for closure effects deduced from the $\mathrm{R}$ ratio. The meaning of "constant $\Delta \mathrm{K}_{\mathrm{I}}$ tests" is also questionable in view of the large gradient in $\mathrm{K}_{\mathrm{I}}, \mathrm{K}_{\mathrm{II}}$ and $\mathrm{K}_{\mathrm{III}}$ along the front of a partially or completely slanted crack and of the reduction in $\Delta \mathrm{K}_{\mathrm{I}}$ associated with crack twisting.

Walker et al [6] first reported an influence of environment on shear lips development in titanium alloys. The corrosive environment appeared to postpone crack twisting in Ti-8Al-1Mo-1V, while no systematic effect was found in Ti-6Al-AV. Vogelesang and Schijve [2] observed complete crack twisting in 7075 T651 aluminium alloy for a lower apparent $\Delta \mathrm{K}_{\mathrm{I}}$ in vacuum than in air and for a higher apparent $\Delta \mathrm{K}_{\mathrm{I}}$ in $3,5 \% \mathrm{NaCl}$ solution. Horibe et al [5] reported a similar effect of salt water in low strength steel, but a less pronounced effect of environment for high strength steel.

In an effort toward 3D analysis, Pook [8] performed finite element computations of the stress intensity factors along the front of a fully slanted crack in specimens of different thickness. He found that $\mathrm{K}_{\mathrm{I}}$ is 0.51 to 0.71 smaller than its apparent value (computed in 2D for a normal crack of same length) that $\mathrm{K}_{\mathrm{III}}$, has the same order of magnitude as KI, while $\mathrm{K}_{\mathrm{II}}$ raises near the free surfaces with a skew-symmetric profile. Bakker [9] performed 3D finite element computations of stress intensity factors for fully or partially slanted crack. However, as in the case studied by Pook, a straight crack front was considered, while tunnelling probably plays a role in crack twisting in fatigue.

The aim of the present work is to re-examine the problem on a 3D basis, including a 3D experimental characterization of the crack paths and kinetics and a 3D numerical analysis of those data. A method to predict the onset of crack twisting is also proposed.

\section{EXPERIMENTAL PROCEDURES}

Fatigue crack growth tests were performed with a frequency of $5 \mathrm{~Hz}$ and $\mathrm{R}=0.1$ on $6 \mathrm{~mm}$ thick, $100 \mathrm{~mm}$-wide, 300mm-high Center Crack Panel specimens. Two material were investigated: $7075-\mathrm{T} 651$ aluminium alloy $\left(\sigma_{0,2}=376 \mathrm{MPa}, \sigma_{\mathrm{u}}=537 \mathrm{MPa}, \mathrm{E}=75 \mathrm{GPa}\right)$ and S355 low-alloy steel $\left(\sigma_{0,2}=349 \mathrm{MPa}, \sigma_{\mathrm{u}}=510 \mathrm{MPa}, \mathrm{E}=205 \mathrm{GPa}\right)$.

Both sides of the specimens were polished to allow crack propagation monitoring with an optical microscope, at a magnification of one hundred. The tests were performed in air or in a transparent reservoir filled with $3,5 \mathrm{~g} / 1 \mathrm{NaCl}$ solution, under different loading amplitudes indicated in Table 1.

Marker block loading sequences with and increased $\mathrm{K}_{\min }$ but the same $\mathrm{K}_{\max }$ were periodically applied, so that the $\mathrm{R}$ ratio became temporary 0.7 , until approximately 100 $\mu \mathrm{m}$ propagation was achieved, in order to mark the position of the crack front and be able to derive the mean crack growth rate between consecutive markings, for any point along the front. Ten to twelve marker blocks were applied at $20 \mathrm{~Hz}$. To characterize crack front tunnelling, the difference in crack length between the mid-thickness and the average length on free surfaces was measured and denoted by $\Delta$ a. 
Table 1: Test conditions

\begin{tabular}{|c|c|c|c|c|c|c|}
\hline material & \multicolumn{4}{|c|}{$7075 \mathrm{~T} 651$} & \multicolumn{2}{c|}{ S355 steel } \\
\hline${\text { Test } \mathrm{n}^{\circ}}^{\circ}$ & ccp2a & ccp2Na & ccp7a & ccp5a & ccp2s & ccp3Ns \\
\hline environment & air & $\mathrm{NaCl}$ & air & air & air & $\mathrm{NaCl}$ \\
\hline $\begin{array}{c}\text { Range of apparent } \\
\Delta \mathrm{K}_{\mathrm{I}}(\mathrm{Mpa} \sqrt{\mathrm{m}})\end{array}$ & $7-18$ & $7-18$ & $6-20$ & $9-20$ & $18-60$ & $18-60$ \\
\hline stress range $(\mathrm{MPa})$ & 34 & 34 & 35 & 40 & 100 & 100 \\
\hline notch width $(\mathrm{mm})$ & 15 & 15 & 10 & 15 & 10 & 10 \\
\hline $\begin{array}{c}\text { cycles for crack } \\
\text { initiation }\end{array}$ & 30000 & 10000 & 23000 & 15000 & 35000 & 27000 \\
\hline $\begin{array}{c}\text { cycles of crack } \\
\text { growth until fracture }\end{array}$ & 202440 & 110260 & 163000 & 59000 & 157730 & 138730 \\
\hline
\end{tabular}

The topography of the fracture surfaces were reconstructed, thanks to digital optical microscopy (fig. 1).The magnification used for image capture was 50 and 13 images had to be stitched to map the whole crack from the notch root to the onset of ductile fracture. The results were obtained as $(\mathrm{x}, \mathrm{y}, \mathrm{z})$ triplets, where $\mathrm{x}$ denotes the distance from the notch root along the free surface, $y$, the position in depth, and $\mathrm{z}$ the height from the notch plane (see fig 1), with a step of $4.5 \mu \mathrm{m}$ in the $\mathrm{xy}$ plane and $35 \mu \mathrm{m}$ in the $\mathrm{z}$ direction. Longitudinal and transverse height profiles, $\mathrm{z}(\mathrm{x})$ or $\mathrm{z}(\mathrm{y})$ were derived. Polynomial expressions were fitted to these profiles and used to compute the local tilt and twist angles as $\operatorname{arctang}(\mathrm{dz} / \mathrm{dx})$ and $\operatorname{arctang}(\mathrm{dz} / \mathrm{dy})$, respectively. The shear lips width, denoted by $t_{s}$, was also deduced from the transverse height profiles.

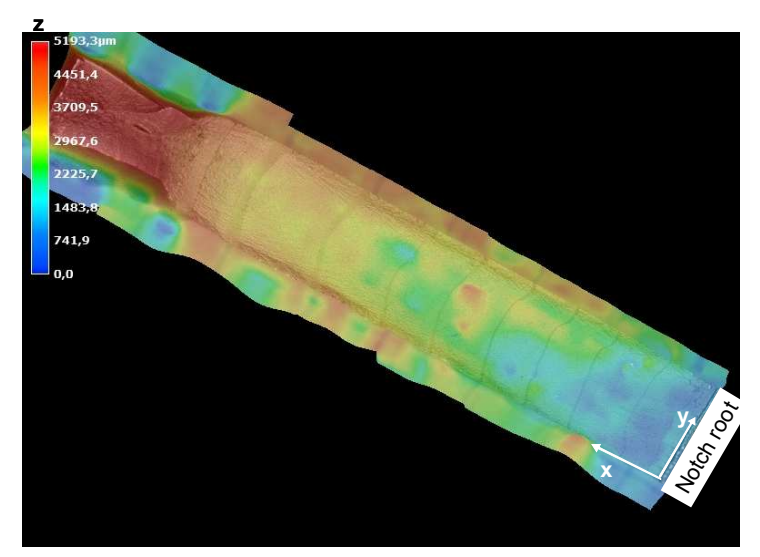

Figure 1: Topography of the fracture surface of specimen ccp2s. 


\section{EXPERIMENTAL RESULTS}

For a given loading range, the presence of a $\mathrm{NaCl}$ solution reduced the number of cycles for crack initiation, by a factor of 3 in the aluminium alloy and 1.3 in steel, as shown in Table 1. Crack growth was also substantially accelerated by the $\mathrm{NaCl}$ solution in the aluminium alloy, but the acceleration was rather limited in steel.

\section{Crack paths}

Figure 2 shows examples of crack longitudinal and transverse profiles, $\mathrm{z}(\mathrm{x})$ and $\mathrm{z}(\mathrm{y})$, plus twist angle profiles in 7075 aluminium alloy and S355 steel, at different stages.
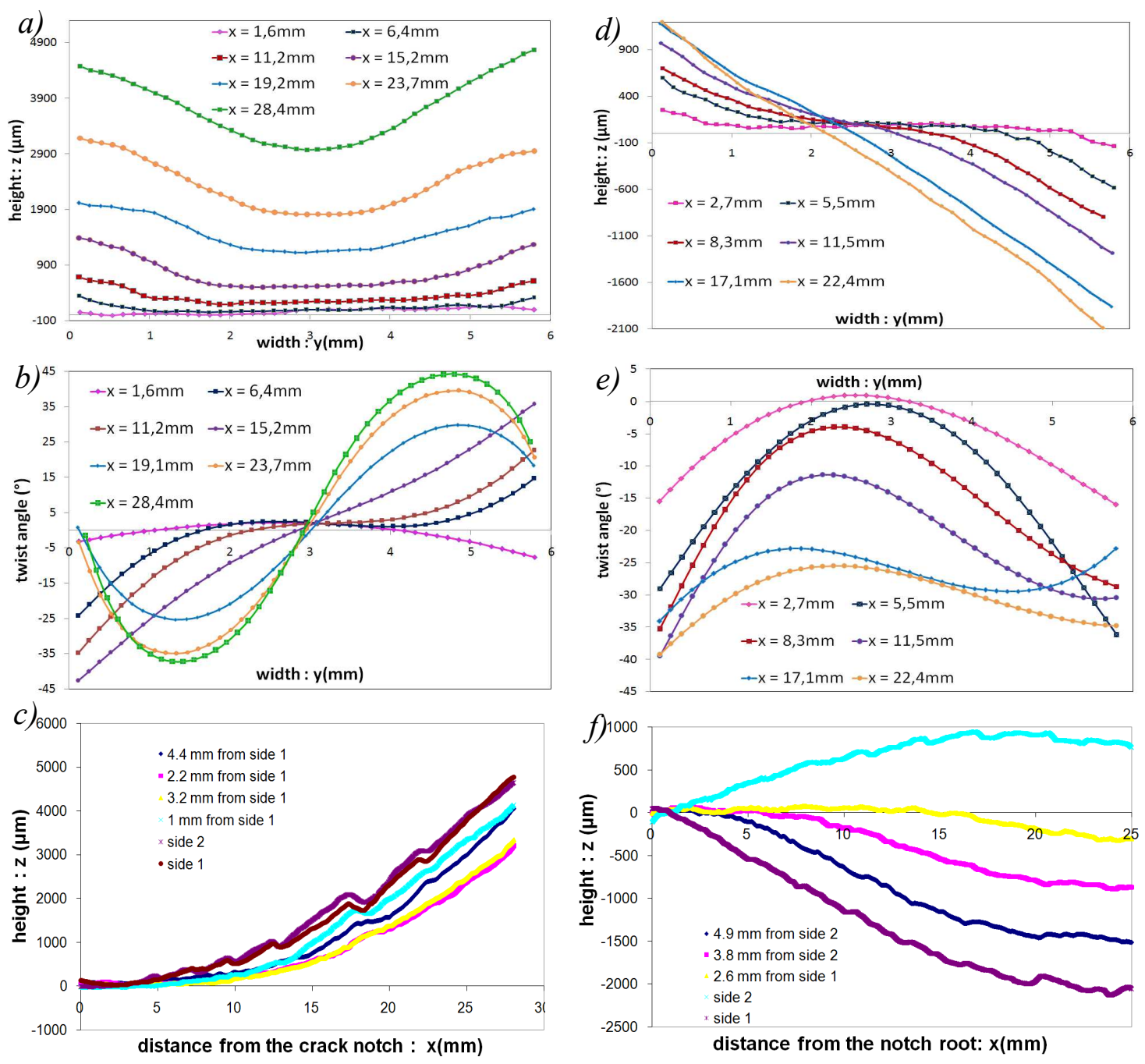

Fig 2: Topographic reconstructions. a) $z(y)$ b) twist angle and c) $z(x)$, specimen ccp5a .d) $z(y)$ e) twist angle f) $z(x)$, specimen ccp2s. 
In the aluminium alloy, the two slanted parts are facing each other (fig. 2a) and the progressive increase in mean $\mathrm{z}$ denotes a tilt of the crack, by approximately 16 degrees, even in the central part, more apparent on Fig. 2c. The twist angle is neither uniform along the shear lip, nor constant as the crack grows. It is substantially less than $45^{\circ}$ and its absolute value tends to drop near side surfaces.

In steel, the shear lips initiated on each side share a similar orientation. The mean height of the crack remains nearly constant, due to a nearly skew-symmetric distribution of the tilt angle along the front, as shown on fig. $2 \mathrm{~d}$.

Kinks corresponding to marker blocks with the same $K_{\max }$ but a lower $\Delta \mathrm{K}$ can be noticed on fig. $2 \mathrm{c}$ and $\mathrm{d}$. During these cycles, the tilt angle is temporary reduced. The fact that the crack tends to go back to plane propagation while $K_{\max }$ is unchanged prooves that crack deviation, is not controlled by the peak load, but by the amplitude, ie: by cyclic plasticity, as also found by others. [1-7].

The evolutions of the shear lips width in air and $\mathrm{NaCl}$ solution under the same mechanical conditions are compared on fig 3.
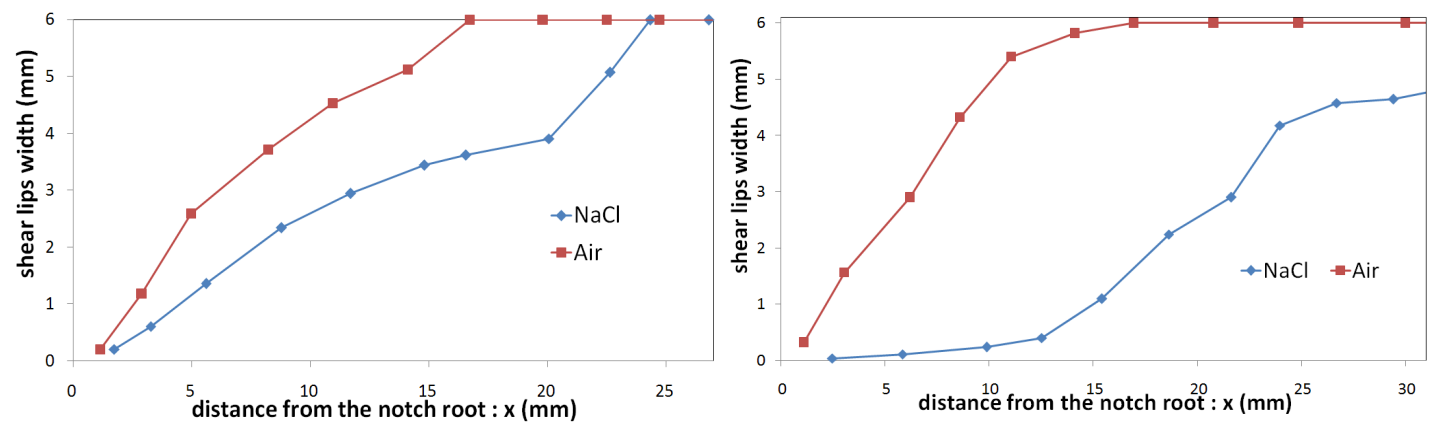

Fig 3: shear lips width evolution in air and $\mathrm{NaCl}$ solution in 7075-T6 aluminium for $\Delta \sigma=34 \mathrm{MPa}$ and $\mathrm{S} 355$ steel, for $\Delta \sigma=100 \mathrm{MPa}$

Shear lips development was delayed and less complete in the $\mathrm{NaCl}$ solution, in agreement with some observations from the literature [2, 5]. Fig. 4 shows the shape and successive positions of the crack front and the boundary of the flat or slanted areas.
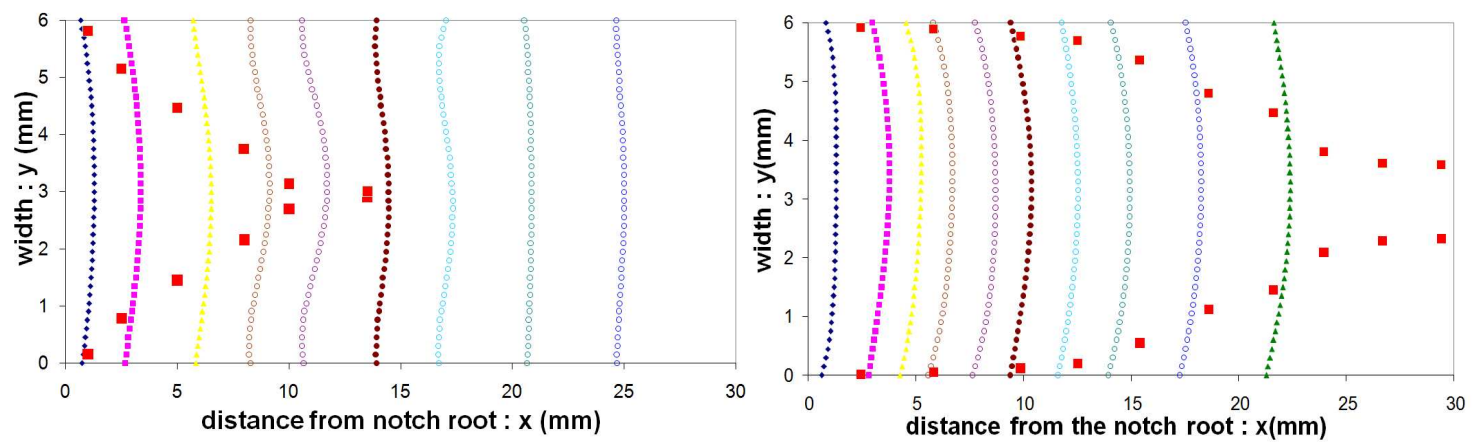

Fig 4: shape and successive positions of the crack front in S355 steel $\Delta \sigma=100 \mathrm{MPa}$ in air and salt water. The red dots represent the boundary of normal or slanted areas 
The evolution of crack front tunnelling, $\Delta \mathrm{a}$, is plotted on fig 5

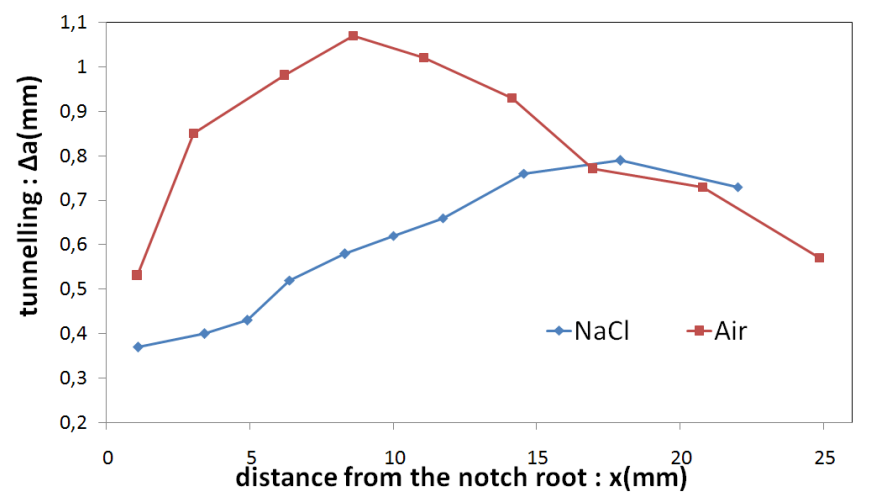

Fig 5: degree of crack front tunnelling, in steel $\Delta \sigma=100 \mathrm{MPa}$ in air and $\mathrm{NaCl}$ solution

In air, tunnelling was progressively reduced and cancelled by the development of shear lips, in spite of a drop in nominal $\Delta \mathrm{K}_{\mathrm{I}}$ in the slanted zones and in spite of a probable local increase in closure effects, which are generally more important at low $\Delta \mathrm{K}_{\mathrm{I}}$. Both factors should reduce the crack growth rate near the free surfaces and thus increase the convexity of the crack front. The contrary is in fact observed and the reduction in tunnelling provides an evidence for an effective contribution of shear modes to the crack driving force in slanted zones.

However, in both materials, fractographic observations revealed fatigue striations in the normal zones as well as in the slanted areas, where a few isolated rubbing marks were also observed near the side surfaces in aluminium specimens. Hence mode I still contributes to crack growth in the slanted zones and it would be incorrect to describe crack twisting as a transition from tension to shear-mode as sometimes done.

Note on fig. 4 that the intersection angle of the crack front with the free surfaces is initially close to the value computed by Bazant et al. [11] for mode I loading: $101^{\circ}$ for a Poisson's ratio of 0.3 , but that it is reduced in the slanted zones, because of the presence of mode II and III for which the angle should be closer to $67^{\circ}$ [11].

\section{NUMERICAL STUDY}

The numerical study is constituted of two parts: an elastic analysis in an extended finite element code (X-FEM, implemented in code Aster at EDF R\&D) well fitted to estimate the stress-intensity factors (SIFs) taking into account the real crack geometry of slanted cracks, but not suitable for the simulation of cyclic plasticity, which was done in the framework of the classical finite element method, but limited to flat tunnelling cracks. 


\section{A. The X-FEM computation}

\section{A.1. General framework}

The extended finite element method, introduced by Moes et al. [12], allows the simulation of complex crack shapes where the structural finite element mesh does not have to conform to the crack surface. The crack surface and its front are defined geometrically by two signed distance functions named "level sets". In order to take into account the displacement jump due to the presence of the crack and the crack tip singularity the discretized displacement field is "enriched" with discontinuous shape functions. The displacement field is approximated as follows:

$$
\underline{u}(\underline{x})=\sum_{i \in I_{0}} N_{i}(\underline{x}) \cdot \underline{u_{i}}+\sum_{i \in I_{H}} N_{i}(\underline{x}) H(\underline{x}) \cdot \underline{a_{i}}+\sum_{i \in I_{\gamma}} N_{i}(\underline{x})\left(\sum_{k=1 . .4} \gamma_{k}(\underline{x}) \cdot b_{i, k}\right)
$$

where $\mathrm{H}$ denotes the Heavyside function :

$$
H(x)=\left\{\begin{array}{l}
-1 \text { if } x<0 \\
+1 \text { if } \quad x>0
\end{array}\right.
$$

$\mathrm{I}_{0}$ is the set of the standard finite element nodes, $\mathrm{I}_{\mathrm{H}}$ the set of nodes whose support is completely cut by the crack and $\mathrm{I}_{\gamma}$ the set of nodes whose support contains the crack front, $\mathrm{a}_{\mathrm{i}}$ and $\mathrm{b}_{\mathrm{i}, \mathrm{k}}$, the corresponding additional degrees of freedom. $\mathrm{N}_{\mathrm{i}}$ are the standard finite element shape functions, $u_{i}$ the nodal displacements and $\gamma_{k}$ is the base of Westergaard's solution representing the asymptotic displacement field at the crack tip of a semi-infinite crack in an infinite medium:

$$
\gamma_{k}(\underline{x})=\left\{\sqrt{r} \sin \left(\frac{\theta}{2}\right), \sqrt{r} \cos \left(\frac{\theta}{2}\right), \sqrt{r} \sin \left(\frac{\theta}{2}\right) \sin (\theta), \sqrt{r} \sin (\theta) \cos \left(\frac{\theta}{2}\right)\right\}
$$

\section{A.2. Representation of the crack.}

One of the ways to generate the level-sets used for the crack representation is to mesh both the crack surface and the crack front. This mesh is used only for the geometrical description of the crack and not for the resolution of the problem. An algorithm was thus developed to turn the measured topographic data, that is: a set of $(\mathrm{x}, \mathrm{y}, \mathrm{z})$ triplets plus polynomial fits of crack front markings, into a mesh representative of the crack.

The first step is to fit a polynomial interpolation to the cloud of points extracted from the topography, using the least square method, in 3D. Then a regular, flat grid of points is deformed, using both the equation of the crack surface $\mathrm{z}(\mathrm{x}, \mathrm{y})$, and the polynomial fit of its front, $\mathrm{x}(\mathrm{y})$ (fig.6). This grid is then meshed with quadrangles and the linear elements of the crack front are extracted. 

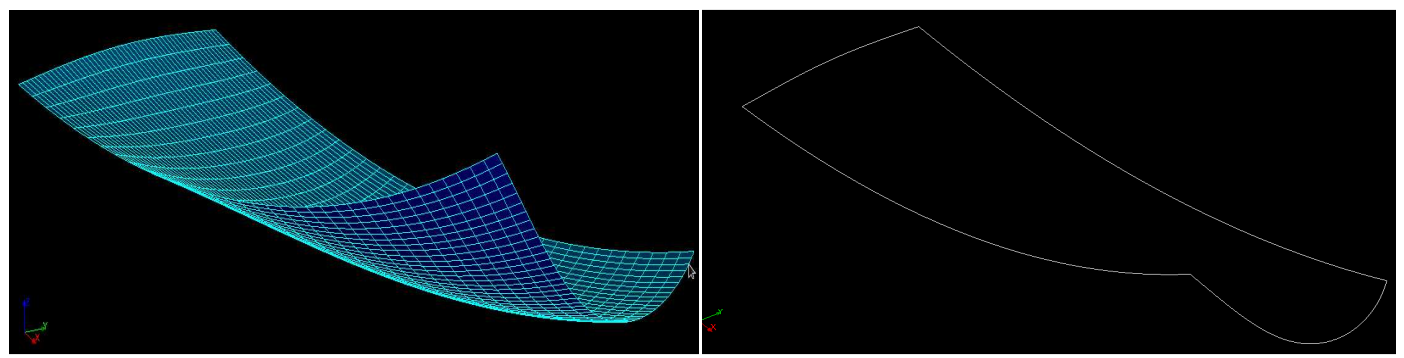

Fig 6: example of mesh of a crack surface used for level-sets computation

The error on $\mathrm{z}$ between the real cloud of points and its polynomial interpolation was estimated as $187 \mu \mathrm{m}$, in average. The G- $\theta$ method, first proposed by Destuynder et al. [13] was used for the computation of SIFs. Due to corner point singularities [11] the values computed at surface points, which are not valid SIFs, were not included in the analysis.

\section{A.2. The structural mesh.}

Half of the CCP specimen was modelled with linear hexahedral $(50 \mu \mathrm{m} * 50 \mu \mathrm{m} * 50 \mu \mathrm{m})$ elements in a parallalepidal zone centered at the crack tip, linked to tetrahedral elements, via pyramidal elements, out of the process zone. The boundary conditions are indicated on fig. 7.
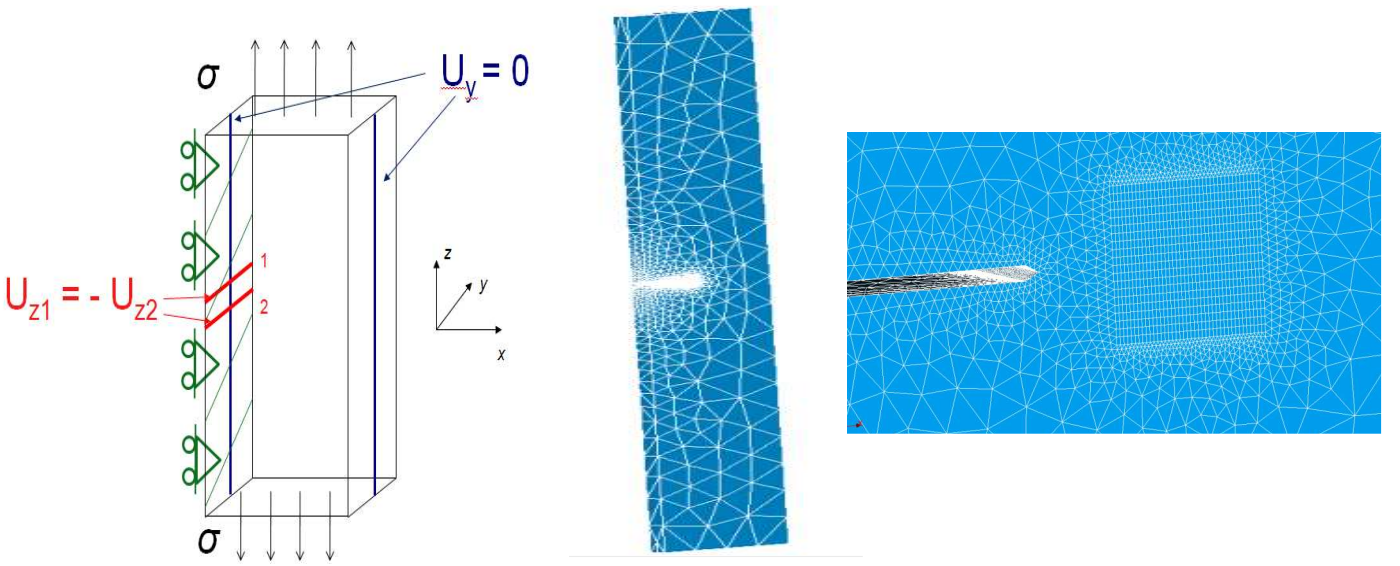

Fig 7: Boundary conditions and mesh of the CCP specimen in the X-FEM model

\section{B. Elastic-plastic finite element analysis}

This part focuses on the onset of crack twisting and thus considers flat, normal cracks, but takes into account the tunnelling of their front. Only a quarter of the CCP specimen was modelled, taking advantage of the symmetries, integrated in the boundary conditions. A 3D mesh with a straight crack front was first prepared, using linear elements, $30 * 30 * 150 \mu \mathrm{m}$ wide near the crack front. This size gives 40 nodes along the front. The area near the front was then deformed, using the polynomial equation describing best the tunnelling front (figure 8). 


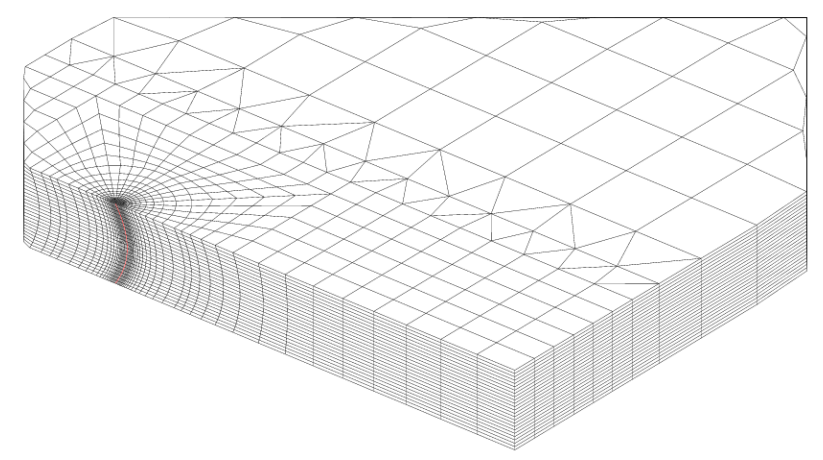

Figure 8: detail of the F.E. mesh showing the tunnelling crack front

Elastic-plastic constitutive equations with isotropic and non-linear kinematic hardening, identified from during push-pull test data on $7075 \mathrm{Al}$ alloy were used.

Cyclic loading with $\mathrm{R}=0.1$ was simulated. The stress and strain fields computed at maximum and minimum load were used for a local application, ahead of each node of the front, of a fatigue criterion derived from that identified by Zhao and Jiang from an extensive multiaxial fatigue database on 7075 T6 [14]. Their criterion successfully captured the transition in fracture mode observed in torsion as well as in push-pull or combined loading: when the loading range increases, fatigue damage changed from normal-stress-driven to shear-driven, yet with an assistance of an opening stress. Their damage function (DF) was thus:

$$
\begin{gathered}
D F=2 b \Delta \varepsilon_{n}\left\langle\sigma_{n \max }\right\rangle+\frac{1-b}{2} \Delta \tau \Delta \gamma \\
b=\left\langle a_{1}-a_{2} \Delta \sigma_{e q}\right\rangle
\end{gathered}
$$

in which $<\mathrm{x}>$ denotes the positive part of $\mathrm{x}, \mathrm{a}_{1}$ and $\mathrm{a}_{2}$ two fitted constants ( 0.862 and $0.00125), \Delta \varepsilon_{\mathrm{n}}, \Delta \gamma, \Delta \tau, \sigma_{\mathrm{nmax}}$, respectively the normal strain, shear strain and stress range and peak opening stress, all computed along the critical plane. The latter is that for which the damage function, DF is maximum. As a consequence of eq. $4 \mathrm{~b}$, this plane changes progressively from the maximum normal strain to the maximum shear plane when the loading range increases.

In the present study, this criterion was slightly modified. Since the transition in fracture mode occurs in the low-cycle fatigue range, the equivalent strain range, rather than the stress range, is assumed to control the critical plane. Equation $4 \mathrm{~b}$ was thus turned into:

$$
b=\left\langle 1-\frac{2 . \Delta \varepsilon_{e q}}{\Delta \varepsilon_{e q_{\text {trans }}}}+\left(\frac{\Delta \varepsilon_{e q}}{\Delta \varepsilon_{e q_{\text {trans }}}}\right)^{2}\right\rangle
$$

in which $\Delta \varepsilon_{\text {eq,trans }}$ corresponds to the equivalent strain range for which the transition from one fracture mode to the other is observed, that is near $0.092 \%$ for the material 
investigated. A smoother evolution of $b$ is predicted near the transition, compared to equation $4 \mathrm{~b}$. In addition, $\mathrm{b}$ is equal to 1 at low strain range, so that fracture is controlled merely by the normal stress and strain, which is not the case in the original criterion, for which the maximum $b$ is 0.862 . To apply the criterion ahead of each node of the crack front, $\Delta \varepsilon_{\text {eq }}$ was first averaged over a distance $\mathrm{L}=90 \mu \mathrm{m}$. The local value of $\mathrm{b}$ was then computed using eq. 5 . Then the damage function, DF was computed along all potential twisted planes, for a twist angle $\theta$ ranging from 0 to $45^{\circ}$. The value of $\theta$ corresponding to the maximum DF provided the local direction of crack extension.

\section{NUMERICAL ANALYSIS OF THE EXPERIMENTAL RESULTS}

\section{Computed SIFs and analysis of crack growth rates}

Figure 9 shows the computed $\mathrm{K}_{\mathrm{I}}, \mathrm{K}_{\mathrm{II}}$ and $\mathrm{K}_{\mathrm{III}}$ profiles at peak load along the first and eight crack front in specimen CCP5a. While mode I prevails, as expected, when the crack plane is still normal to the loading axis, mode III and -to a lesser extent- mode II increase significantly when slanted crack growth occurs.
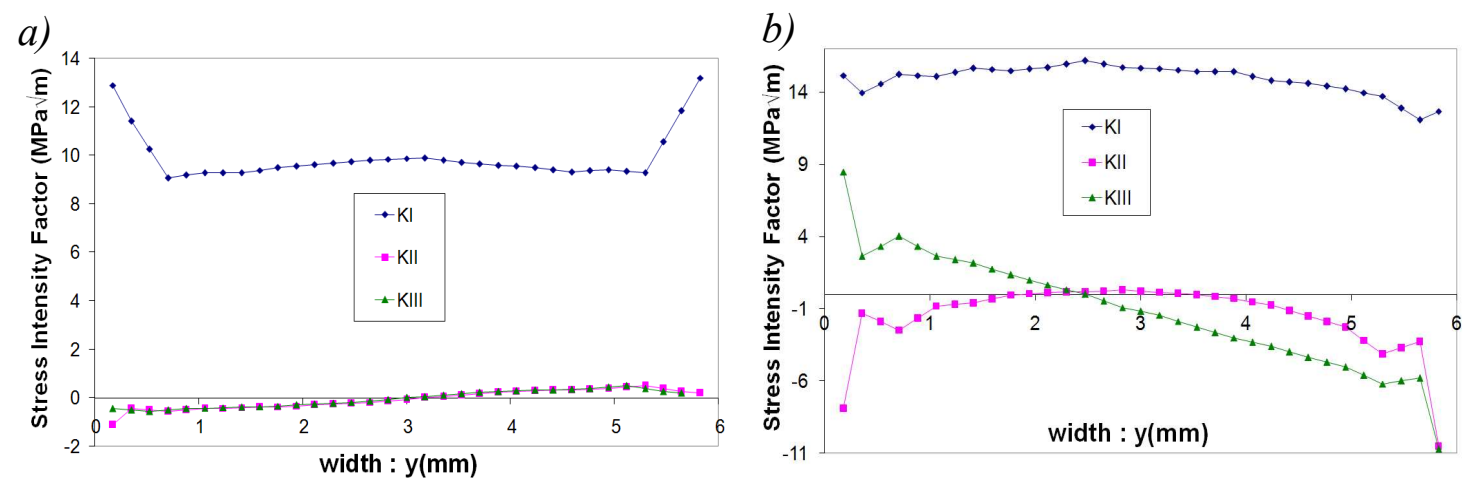

Figure 9: SIFs at peak load along a) the 1st and b) 8th front, specimen CCP5a.

The crack growth rates measured at various depth in the same specimen are correlated to $\Delta \mathrm{K}_{\mathrm{I}}$ on Figure $10 \mathrm{a}$ and to $\Delta K_{e q}=\sqrt{\Delta K_{I}^{2}+\Delta K_{I I}^{2}+\frac{\Delta K_{I I I}^{2}}{(1-v)}}$ on fig. $10 \mathrm{~b}$. While $\Delta \mathrm{K}_{\mathrm{I}}$ fails to correlate all the data -with an upward curvature of the kinetic curve for surface points-, $\Delta \mathrm{K}_{\mathrm{eq}}$ provides a much better correlation, which provides additional evidence that the opening and shear modes cooperate for slanted crack growth. 

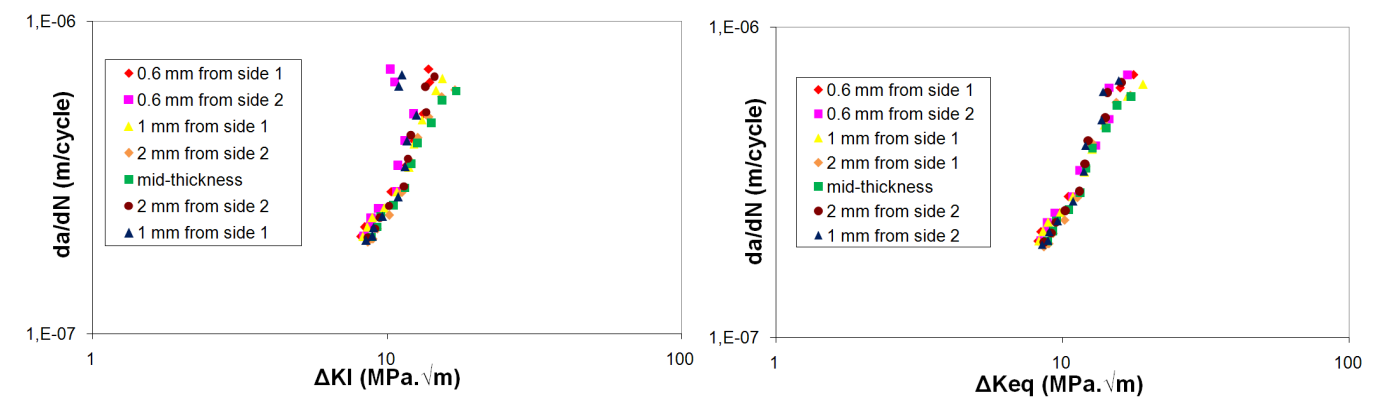

Figure 10: Correlation of crack growth rates with $\Delta \mathrm{K}_{\mathrm{I}}$ or $\Delta \mathrm{K}_{\mathrm{eq}}$, specimen ccp5a.

\section{Analysis of crack paths based on the local approach}

Figure 11 shows the computed profiles of Von Mises equivalent strain range ahead of the successive crack fronts for tests ccp7a (stress range $34 \mathrm{MPa})$ and ccp5a (40MPa). Since $\Delta \mathrm{K}_{\mathrm{eq}}$ increases as the crack grows, so does the equivalent strain range, which is higher for ccp5a than for ccp7a.
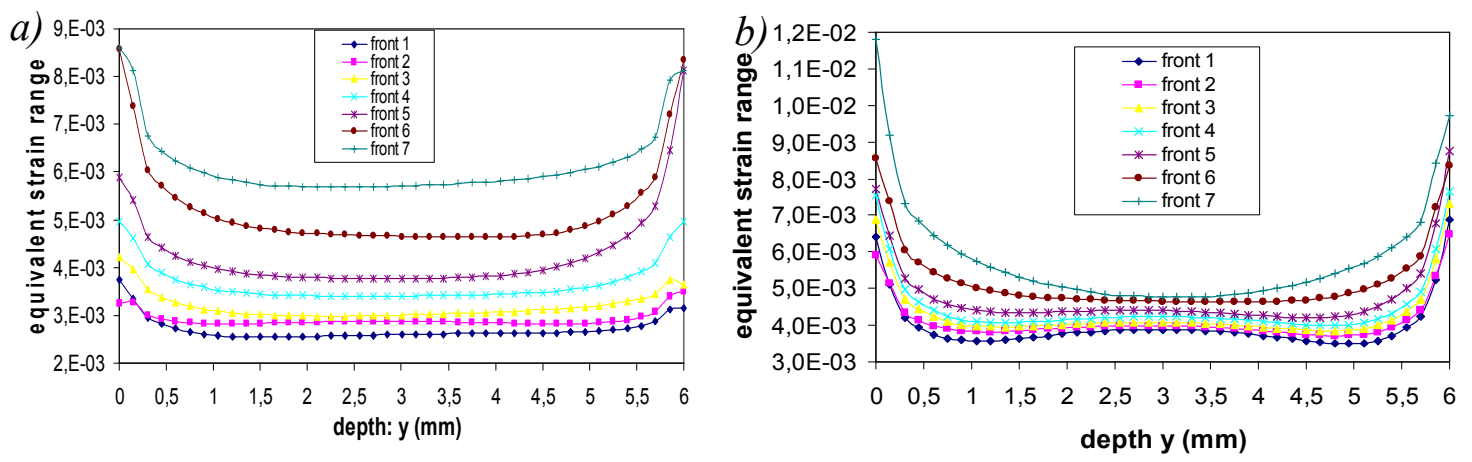

Figure 11: Profiles of $\Delta \varepsilon_{\text {eq }}$ ahead of the crack fronts for a) test ccp5a and b) ccp7a

Figure 12 shows the profiles of predicted twist angles for those two specimens. A progressive increase in twist angle, $\theta$, as the crack grows is predicted near the free surfaces where the drop in $\theta$ noticed on fig. $2 b$ and $2 \mathrm{e}$ is qualitatively captured.
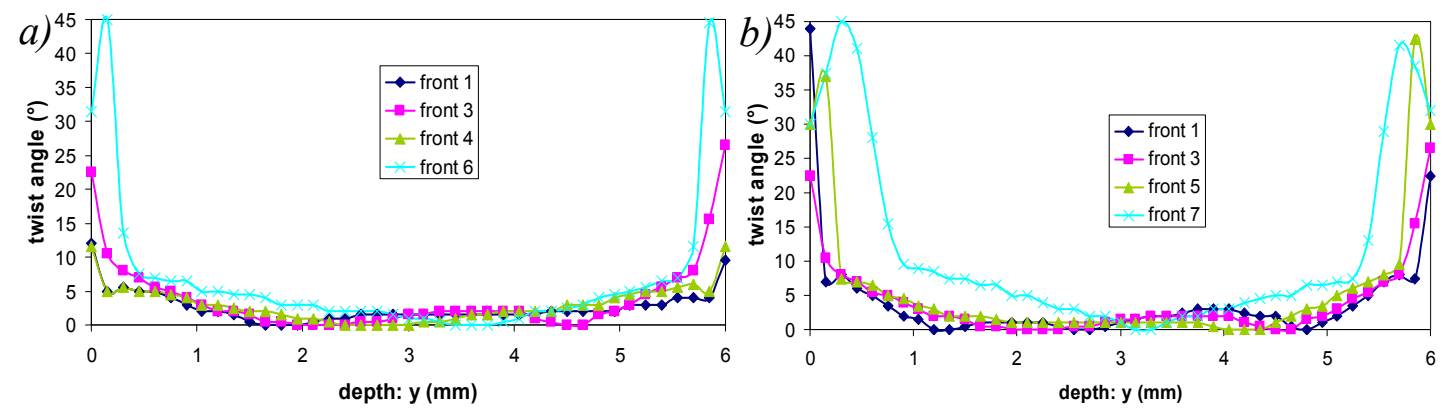

Figure 12: Profiles of predicted twist angles for a) ccp5a and b) ccp7a

The shear lips width, $\mathrm{t}_{\mathrm{s}}$, was computed from such profiles, as the part in which $\theta \geq 4^{\circ}$. Figure 13 compares the predicted and measured evolutions of $\mathrm{t}_{\mathrm{s}}$. The model qualitatively captures the progressive increase in $t_{s}$ and the fact that it is larger in the specimen submitted to a loading range. 

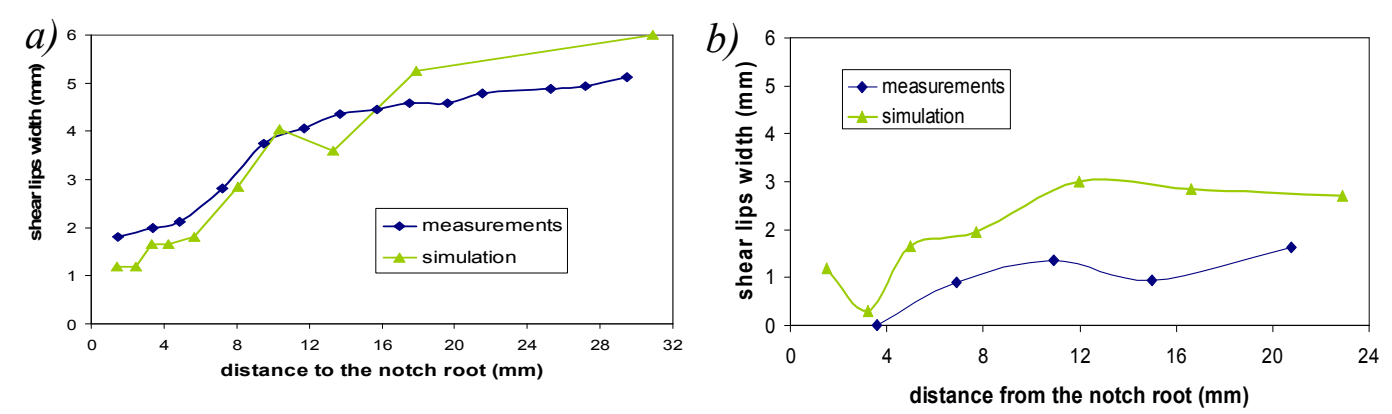

Figure 13: Predicted and measured evolution of shear lips width. a) ccp5a and b) ccp7a.

\section{CONCLUSIONS AND FURTHER WORK}

Fatigue crack paths in thin sheets of aluminium alloy and mild steel were characterized in 3D in air and salt water. The latter tends to stabilize normal crack growth. Both the opening and shear modes contribute to slanted crack growth, whose rate correlates with $\Delta K_{e q}=\sqrt{\Delta K_{I}^{2}+\Delta K_{I I}^{2}+\frac{\Delta K_{I I I}^{2}}{(1-v)}}$ deduced from X-FEM computations on real crack geometries. 3D elastic-plastic F.E. simulations and a local application of a fatigue criterion with a strain range-dependent critical plane qualitatively predicted the transition in crack growth mode in 7075-T651. A similar approach will be attempted for mild steel and the X-FEM method will be modified to incorporate cyclic plasticity and allow prediction of both the crack path and kinetics within a single framework.

\section{REFERENCES}

1. J. Schijve, Eng. Fract. Mech. 14 n4, 1981, 789-800

2. L.B. Vogelesang, J. Schijve (1980), Fat. Fract. Eng. Mat. \& Struct. 3, 85-98

3. J. Zuidema, H.S. Blauw (1988), Eng. Fract. Mech. 29 n4, 401-413

4. J. Zuidema, M. Mannesse (1991), Engng. Fract. Mechanics 40 n $^{\circ} 1,105-117$

5. S. Horibe, M. Nakamura, M. Sumita (1985), 7 n4, 224-227

6. K. Walker, S. Pendleberry, R. McElwee (1970) in: Effects of environment and complex load history on fatigue life, p234-240, ASTM STP 462, ASTM Philadelphia

7. C.M. Hudson, J.T. Scardina (1969), Engng. Fract. Mechanics 1, 429-446

8. L.P. Pook (1993), in "Mixed-mode fracture and fatigue" p 285-302, H.P.

Rossmanith and K.J. Miller eds, ESIS 14, MEP, London

9. A.Bakker (1992), Fat. Fract. Engng. Mat. Struct., 15 n¹1, 1051-1069

10. R.W. Hertzberg, E.F. Von Euw (1971), Int. J. Fracture Mechanics 7, 349-353

11. Bazant S.P, Estenssoro L.F (1979), Int. J. Solids \& Structures 15, 405-426

12. N. Moes, J. Dolbow and T. Belytschko, (1999) Int. Journ. Numerical Methods in Engineering $46 \mathrm{n}^{\circ} 1,131-150$

13. P. Destuynder, M. Djaoua (1981), Math.meth.in the Appl.Sci., 3, 70-87

14. T. Zhao, Y. Jiang (2008), Int. J. Fatigue 30 834-84 